Годишник Телекомуникации 2020, том 7, с. $49-55$

Yearbook Telecommunications 2020, vol. 7, p. 49-55

eISSN 2534-854X

https://telecommunications.nbu.bg/bg/godishnik-telekomunikacii

DOI: https://doi.org/10.33919/YTelecomm.20.7.6

ОТРАЖЕНИЕ ОТ ВЛИЗАНЕТО НА БЪЛГАРИЯ В ЕВРОЗОНАТА ЗА БАНКОВИЯ И ЗА РЕАЛНИЯ СЕКТОРИ В РЕПУБЛИКА БЪЛГАРИЯ И В ЧАСТНОСТ ЗА ОТРАСЬЛ ,ТЕЛЕКОМУНИКАЦИИ“

Йосиф Аврамов

\title{
IMPACT OF BULGARIA'S ENTRY IN THE EURO AREA FOR THE BANKING AND REAL SECTORS IN THE REPUBLIC OF BULGARIA AND IN PARTICULARLY FOR THE TELECOMMUNICATIONS INDUSTRY
}

\author{
Joseph Avramov
}

\begin{abstract}
Резюме: В публикацията са анализирани предимствата на влизането на Република България във валутния механизъм ERM 2 и в банковия съюз. В първата и част са посочени кои са ползите за нашата страна за банковия сектор на българската икономика, респективно и за улесняване на разплащанията на фирмите и за гражданите. Във втората част на публикацията са визирани кои са предимствата за реалния сектор на българската икономика, респективно и за отрасъл „Телекомуникации“. В заключение са посочени и някои не особено съществени недостатъци, които ще се появят след присъединяването на България към еврозоната.

Ключови думи: евро, еврозона, валута, банки, разходи
\end{abstract}

\begin{abstract}
The publication analyzes the advantages of the entry of the Republic of Bulgaria into the ERM 2 currency mechanism and the banking union. The first part indicates the benefits for our country for the banking sector of the Bulgarian economy, respectively for facilitating the payments of companies and citizens. The second part of the publication refers to the advantages for the real sector of the Bulgarian economy, respectively for the Telecommunications sector. In conclusion, some not very significant shortcomings are indicated, which will occur after Bulgaria's accession to the euro area.
\end{abstract}

Keywords: euro, eurozone, currency, banks, costs

\section{1. ВЪВЕДЕНИЕ}

На 10.юли 2020 г. министрите на финансите на страните от Еврогрупата и УС на Европейската централна банка (ЕЦБ) след няколкократно отлагане, постановиха с решение да поканят Република България и Република Хърватия във валутния механизъм EPM 2 и в Банковия съюз. Съгласно утвърдената практика досега нашата страна е възможно да бъде приета в еврозоната след две години престой във валутния механизъм и по всяка вероятност още една година подготовка за влизането ѝ. Това е възможно да се осъществи само при отговор на поставените пред нея показатели за членство в нея. Основателен е въпроса дали е възможно това да се осъществи, както и какви ще са предимствата и какви ще са недостатъците за стопанския живот у нас, за банковата ни система и за българския гражданин и данъкоплатец от членството ни в еврозоната? Предходното правителство и БНБ възприеха неотдавна като възможна дата за присъединяването ни към тази зона на ценова стабилност и просперитет - 01.01.2024 г. Според автора това е постижима цел при положение, че у нас се установи в следващите три години политическа стабилност и при положение, че няма да има резки флуктуации в темповете на икономическото ни развитие. Почти една година по-късно нашата страна се придвижва към тази цел сравнително успешно, при това в условията на криза от Ковид 19. 
Предприятията от отраслите в българската индустрия, които са ориентирани към износ, в т.ч. и от сектор „Телекомуникации“ са в относително добро състояние и в изминалия програмен период 2014-2020 г. някои от тях направиха инвестиции в иновации и модернизация на технологичното си оборудване.

Сравнително скоро българската икономика и българският потребител следва да се възползват от основните преимущества от влизането ни в еврозоната, като: стабилна валута, ниска инфлация и ниски лихвени проценти, прозрачност на цените, премахване на разходите за обмен на валута, по-интегрирани финансови пазари с подходящо ниво на регулиране и надзор, по-ефикасна икономика, рамка на по-стабилни публични финанси, по-силен глас на България в еврогрупата, улесняване на международната търговия и постигане на реален символ на европейската идентичност. Фирмите от еврозоната, които се разплащат в евро, в значително по-малка степен са уязвими на глобални валутни колебания. Предимствата за България от влизането ѝ в еврозоната могат да се групират предимно като икономически и банкови. Ето защо е необходимо да се посочи също, че няма предпоставки левът да се обезцени, преди или при влизането на България в еврозоната и сегашното съотношение на лева спрямо еврото дотогава ще остане непроменено - 1 евро за 1.95583 лв.

Република България понастоящем е страна със стабилна макроикономическа перспектива, доста приличен инвестиционен кредитен рейтинг, както и с добро състояние на текущата и капиталовата си сметки. За съжаление очакванията на автора визираните позитиви да генерират привличането на повече инвестиции, както чуждестранни, така и местни не се оправдаха и в последната 2020 г. те намаляват, като основна причина за това е и кризата, настъпила и у нас, свързана с пандемията Ковид 19. С влизането на България в еврозоната със сигурност ще се подобри дългосрочната перспектива за ръст на БВП у нас. Република България ще има за своя национална валута втората по употреба в международната тьрговия и на финансовите пазари валута - еврото (след щатския долар), а също и трайна стабилност от паричната политика, установена от Европейската централна банка. Тя ще упражнява надзор и над значимите банки у нас, както и в останалите страни в еврозоната. Това обстоятелство ще допринесе бизнес климата в нашата страна чувствително да се подобри и България вече да не е рискова страна и да стане по-привлекателна дестинация за чуждестранните инвестиции.

Еврото ще допринесе за разрешаване на редица икономически проблеми в България, както и за повишаване на доверието към страната от страна международната финансова общност. Присъединяването на България към еврозоната ще е предпоставка за влизането ни в Организацията за икономическо сьтрудничество и развитие (ОИСР), в която членуват понастоящем най-развитите страни в света. През пролетта на 2021 г. правителството ни прие пътна карта за присъединяването на България към ОИСР. Очаква се след това да се повиши както кредитния рейтинг на страната, така и да се увеличи обема на чуждестранните инвестиции у нас. Очаква се също след влизането ни в еврозоната да се осъществят дълго отлаганите реформи в българската икономика, да нарасне конкурентоспособността ѝ, администрацията ни да стане по-ефективна, както и у нас да се приеме по-гъвкаво и по-ефективно трудово законодателство. Понастоящем в БНБ има депозиран правителствен фискален резерв, който понастоящем не бива да бъде по-нисък от 6,2 млрд. лв. Този резерв служи като гарант за фискалната политика, респективно на валутния борд. След като България влезе в еврозоната ще е възможно този резерв да се употреби за развитие на иновациите и от него да се осигурят с финансов ресурс редица социални проекти (например: за строеж на социални жилища за млади семейства, уютни домове за възрастни хора или за жилища от семеен тип за деца без 
Годишник Телекомуникации 2020, том 7, с. 49-55

Yearbook Telecommunications 2020, vol. 7, p. 49-55

eISSN 2534-854X

https://telecommunications.nbu.bg/bg/godishnik-telekomunikacii

DOI: https://doi.org/10.33919/YTelecomm.20.7.6

родители), а също и за подобряване на образователната инфраструктура; за по-добро здравеопазване, за усъвършенстване на научната инфраструктура и др.

Има и някои други важни предимствата от въвеждането на еврото в Република България за реалния сектор на българската икономика. Между тях са: значително понижаване на зависимостта от рисковете на обменния курс на търговските дружества и намаляване на валутния риск, в т.ч. и на валутната рискова премия. Тя в известна степен оскъпява инвестициите в страната и се очаква след премахването ѝ да се увеличи размера на чуждестранните инвестиции у нас. Понастоящем в България се работи с български левове, но левът е сравнително рядко употребявана валута и следва постоянно те да се превалутират в банките в евро или в долари. Това води до известни разходи за счетоводството на компаниите у нас и той е в размер на $0.3-0.5 \%$ от БВП, което се равнява на 300-330 млн. лв. Тази сума може да бъде икономисана и прехвърлена за по-рационални инвестиции, като например за внедряване на иновации в индустрията. Посочено бе, че Република България ще се присъедини към еврозоната, която е зона от почти 20 години на ценова стабилност. Цените в България ще бъдат под контрола в регулаторните органи на ЕС в т.ч. и на Европейската централна банка (ЕЦБ). Практика н прибалтийските страни и в другите по-късно присъединили се държави към еврозоната показва, че в тях непосредствено след присъединяването, не се е наблюдавала значителна инфлация на основни стоки, а само известно незначително закръгляване на цените на някои от тях. У нас, предвид ниската покупателна способност на българския потребител, също след присъединяването ни към еврозоната, ще е налице най-вероятно незначителна инфлация. Дори нещо повече, очаква се след въвеждането на еврото у нас, по всяка вероятност цените на част от някои вносни стоки като хардуер, бяла техника и др. ще намалеят. Същевременно доходите от заплати и пенсии ще отбележат известен ръст. Ще настъпи известно улеснение на задграничните пътувания на българските граждани, като на командированите служители, на гражданите, отиващи на лечение, на почивка или на екскурзия в страните от еврозоната, като те ще икономисат средства за обмяна на националната ни валута - българския лев в евро в останалите 19 страни от еврозоната.

Авторьт предвижда се след влизането ни в еврозоната и у нас да открият свои филиали концерни от останалите страни от ЕС, а също и от САЩ, Великобритания (тя вече е извън EC), Бразилия, Индия, Япония и др.). Това ще увеличи доходите на заетите български работници и служители в тях, предвид по-високото възнаграждение в заводите с чуждестранно участие и по този начин се очаква да се редуцира от една страна безработицата у нас, а от друга - да се намали емиграцията на висококвалифицирани български специалисти зад граница. Със сигурност след присъединяването ни към еврозоната ще се увеличат чуждестранните инвестиции у нас. Очакванията на автора са за нарастване на нетният приход от продажба или дългосрочна аренда на земя и на недвижими имоти на чуждестранни инвеститори, което ще даде известен тласък на инвестициите в селското ни стопанство и в хранително-вкусовата ни индустрия. Предстоящо е активирането на свободното движение на капитали, тъй като транзакционните разходи за обмен ще отпаднат, както и ще се елиминират разходите по конвертиране на търговските сделки на наши фирми с компании от други страни от еврозоната. [1]. Очаква се и известно нарастване на инвестициите и в сектор „Телекомуникации“, което ще доведе до по-голямо разнообразие на предлаганите услуги, които ще се извършват при по-високо качество, респективно по всяка вероятност и до намаляване на цените им. 
Необходимо е да се отбележи, че едно от най-съществените предимства от приемането на еврото за българска национална валута, както за реалния сектор така и за банковия сектор у нас е по-голямата сигурност, в случай на финансова криза и/или на временни трусове на световните финансови пазари. При наличие на такива нежелани прецеденти, то се очаква намеса и оказване на помощ на България от страна на ЕЦБ и на Европейския стабилизационен механизъм. От съществено значение за фирмите от страните от еврозоната, е че те се ползват от облекчени лихвени условия по кредитите си и те са средно с 2-3 \% по-ниски от нивата на лихвите у нас понастоящем.

Очаква се у нас след влизането ни в еврозоната лихвените нива да се понижат, както за корпоративните кредити, така и за жилищните и потребителските кредити. По този начин ще нарасне конкурентоспособността на фирмите от българската индустрия в т.ч. и на компаниите от сектор „Телекомуникации“, което е положително за тях. По принцип влизането ни в еврозоната дава по-голяма стабилност на финансовата ни система. Налице са следните предимства от присъединяването ни за единната европейска валута за банковия ни сектор:

- Ще се преустанови изразходването на средства от български компании, в т.ч. и от сектор „Телекомуникации“ за конвертиране на валутните сделки при осъществяване на банковите транзакции, което ще доведе до улесняване на транснационалните разплащания; [2]

- Небанковите ни финансови институции ще осъществяват евентуално по-голям обем на вътрешнообщностни операции. По този начин ще се увеличи броя на активните публични компании, търгувани както на Българската фондовата борса, така и на други борси в страни в ЕС и на други големи борси в света. Ще се увеличат обемите на търговията с ценни книжа на български публични компании, в т.ч. и такива от сектор „Телекомуникации“, което е позитивно обстоятелство за тяхното финансиране, респективно и за тяхната по-добра пазарна капитализация;

- Очаква се да се развият по-добре и застрахователните пазари у нас. На тях ще се предлагат нови застрахователни продукти, а също и нови банково-застрахователни продукти. По този начин кредитите у нас ще се застраховат срещу различни видове рискове, което е в интерес на кредитоискателите от бизнеса;

- Ще се присъжда кредитен рейтинг на българските фирми. Очаква се да започне работа европейска агенция за кредитен рейтинг. След повсеместното рейтинговане на българските фирми, то фирма, която няма рейтинг извънредно трудно би получила голям инвестиционен кредит и от българска банка. Това обстоятелство ще съдейства за понижаване на размера на лихвите по кредитите. [3]

Налице са и известни недостатъци от влизането ни в еврозоната. Някои от тях ще доведат до известни финансови загуби и те не са за подценяване, като:

- Налице е една повече сантиментална причина без да е от особено голямо значение. За някои наши сънародници отказът от лева - националната ни валута в голяма степен е и отказ от българската ни идентичност. Едва ли някой българин с тъга ще „въздиша” дълго време по българския лев. Не е изключено вероятно да има след време наши сънародници, които ще си спомнят, че древните траки са имали свои монети в обращение няколко века пр.н.е. и близо от 2600 години по българските земи са се използвали метални пари, което е признак за икономически просперитет и за висока стопанска култура?!? Подобни чисто сантиментални чувства е имало преди 20 години при въвеждането на еврото през 2002 г. в страни с много по-силни валути от българската - лева, като в Германия или Франция. Понастоящем немските и френските граждани едва ли съжаляват за германската марка и за френския франк и отдавна са свикнали с еврото, което понастоящем е 
Годишник Телекомуникации 2020, том 7, с. 49-55

Yearbook Telecommunications 2020, vol. 7, p. 49-55

eISSN 2534-854X

https://telecommunications.nbu.bg/bg/godishnik-telekomunikacii

DOI: https://doi.org/10.33919/YTelecomm.20.7.6

националната им валута. Ето защо авторьт очаква не период не по-дълъг от 4-5 години след влизането на България в еврозоната и ние - българските граждани да не си спомняме с носталгия за българския лев. Още повече, че на реверса на националните ни евромонети ще има изобразени картини със сюжети от българската история и от българското културно наследство, което е твърде богато, както и от наследството на народите, живели по българските земи.

- Очаква се бюджета на БНБ, респективно и бюджета на България, да претърпят известни загуби от сеньораж. Определението за сеньораж, е доходът под формата на разлика между номиналната стойност на парите и разходите на БНБ или друга централна банка за тяхното създаване (изработване). В последните години размерьт на сеньоража у нас е средно $2,2 \%$ от БВП и е сходна величина с тази в развитите страни. Сеньоражът се определя и като приход от последна инстанция на правителството, който в период на неочаквани кризи може да се ползва за събиране на допълнителни приходи. На практика това няма да донесе на бюджета на страната ни големи финансови загуби.

- Очаква се на първо време да нараснат т. нар. еднократни разходи за въвеждането на еврото. Около 8 \% от БВП са били тези еднократни или предварителни разходи приблизително в 12-те държави, които са въвели първи еврото през 2002 г. и те са: разходи за промяна на цените от левове в евро, които са от чисто техническо естество, като актуални за дадения момент опаковки, на които са обозначени цени в евро, респективно и напечатване на нови етикети с цени в евро за други пообемни стоки, което следва да стане към момента на въвеждането на еврото. Ще се наложат известни разходи и за изготвяне на нови програмни продукти и на нов софтуер, в т.ч. и разходи, свързани с инсталирането му на касовите апарати. Налице ще са и допълнителни разходи за адаптация на счетоводното и финансово управление към новата за България валута, в т.ч. и на информационните системи. Ще се появят известни проблеми при изготвянето на бюджета на българските фирми в евро за годината, през която ще се въведе еврото. Ще се наложи разходването на ресурс за преработката и пререгистрацията в Агенцията по вписванията на учредителните актове на всяка фирма и НПО, в т.ч. и за преработка на техните устройствени правилници. Тези особености при въвеждането на еврото у нас след няколко години ще са валидни и меродавни и за фирмите от сектор „Телекомуникации“;

- Очаква се известно първоначално увеличение на разходите както на държавните органи, така и в известна степен за всяка отделна фирма и по отношение на други аспекти на бизнеса им. Тези разходи ще следва да се извършат и от компаниите от сектор „Телекомуникации“. Те ще бъдат свързани с изготвянето на оценка за очакваното влияние на промяната на националната ни валута - от български лев към евро, върху извършваните операции както с другите фирми от реалната ни икономика, така и с външнотьрговските им контрагенти.

Визираните недостатъци от присъединяването ни към еврозоната не са от твърде съществено значение за развитието на българската икономика, в т.ч. и за банковия ни сектор и са преодолими за не повече от две-три години след влизането на Република България в еврозоната. Предимствата от присъединяването ни са значително повече и са от много по-съществено значение за българската икономика, както и за българските граждани. Ето защо следва в тази връзка да се посочи също, че: 
1. Българският лев по-скоро няма изгледи да се обезцени в периода до момента, когато България влезе в еврозоната и параметрите на валутния борд дотогава няма да бъдат нарушени, т.е. 1 евро ще се обменя за 1.95583 лв. България има стабилна макроикономическа позиция и добро състояние на текущата и капиталовата сметки. При тези показатели левът не само стои стабилно, но дори може да се допусне, че е подценен спрямо еврото. В подкрепа на този извод е и приетия от Народното събрание Закон за изменение и допълнение на Закона за БНБ в началото на 2020 г.

2. След влизането на нашата страна в еврозоната се очаква да се прилагат по-ниски лихви по кредити. Вероятно ще се понижат разходите за междубанкови транзакции. При равни други условия представителите на българския бизнес, а също и българският потребител ще разполагат с по-голям разполагаем финансов ресурс.

3. Република България след влизането ѝ в еврозоната ще стане обект на по-висок инвестиции, както чуждестранни, така и местни инвестиции, които са от български предприемачи. Въвеждането на еврото ще подобри дългосрочните перспективи за икономическия ни растеж, тъй като нашата страна ще има силна международна валута (втората в света след щатския долар), както и устойчива парична и ценова стабилност. Те ще са установени както и за останалите страни, възприели еврото за своя национална валута и са вследствие от паричната политика, както и от надзора над банките от Европейската централна банка. Очакванията ми са, че отрасъл „Телекомуникации“ ще бъде водещ в този бъдещ период по отношение на привличането на чуждестранни инвестиции у нас, които ще са най-вече в изграждането и от трите мобилни оператори, които оперират у нас на 5 G мрежи; инсталиране на широколентов Интернет в отдалечени населени места и т.н.

4. Въвеждането на еврото ще повиши конкурентоспособността на българската икономика и българските предприятия ще са в състояние да изнасят покачествени и по-евтини стоки в чужбина. Очакванията на автора са България плавно да не заема повече последните места в класациите на страните от ЕС Също ще има и други възможности да се възползва от предимствата, които членството в еврозоната ни предоставя, а те са значителни.

5. България от повече от 20 години поддържа строга фискална дисциплина и отговаря на Маастрихтските критерии по отношение на размера на дълга и на дефицита. Ето защо сравнението със ситуацията от преди пет-шест години в южната ни съседка Гърция, както и със сегашната обстановка в тази страна, не е уместно да се прави понастоящем за България и опасенията на някои експерти за бъдещ срив подобен на гръцкия в нашата страна при влизането ѝ в еврозоната са безпочвени.

Правителството на Република България, ако не желае нашата страна и занапред да е сред изоставащите в ЕC, а да е равноправен партньор с останалите държави от сьюза, както и да участва във вземането на всички решения заедно с тях, членството ѝ в еврозоната е напълно естествено и логично. То ще донесе предимно ползи на България и предстои да стане най-значимото събитие за нашата страна след приемането ѝ в ЕС през 2007 г. Понастоящем част от важните решения в ЕС се вземат само от 19-те членки на Еврогрупата, респективно от министрите на финансите на страните от еврозоната.

\section{3. ЗАКЛЮЧЕНИЕ}


Годишник Телекомуникации 2020, том 7, с. $49-55$

Yearbook Telecommunications 2020, vol. 7, p. 49-55

eISSN 2534-854X

https://telecommunications.nbu.bg/bg/godishnik-telekomunikacii

DOI: https://doi.org/10.33919/YTelecomm.20.7.6

В заключение следва да се обобщи, че за представителите на българския бизнес и в частност на тези от тях, ангажирани в сектор „Телекомуникации“ присъединяването ни към валутния механизъм ERM 2 и в Банковия съюз, което стана преди близо една година, както и предстоящото ни влизане в еврозоната, ще е от съществена полза за българските потребители, както и за българските предприятия и ще се отрази позитивно на тяхната конкурентоспособност. Очакванията на автора са оборотите на компаниите, както и печалбите им да нараснат, което ще доведе и до плавно, но сравнително по-бавно нарастване на доходите на заетите работници и служители в тях, респективно и до подобро благосъстояние на българския народ.

\section{ЛИТЕРАТУРНИ ИЗТОЧНИЦИ (REFERENCES):}

[1] АВРАМОВ, Йосиф Аврамов. Еврото - утрешните ни пари. София: Университетско издателство „Св. Климент Охридски“, 2006. ISBN 954-072-232-2. „Evroto - utreshnite ni pari“, Avramov, J, S., 2006, Universitetsko izdatelstvo „Sv. Kliment Ohridski““ [1, c.3]

[2] МИНАСЯН, Гарабед Ардашес. Пътят към евро: Опитът на страните от Източна Европа с Паричен съвет. София: Марин Дринов, 2004. ISBN 954-332-030-1. „Patyat kam evro. Opitat na stranite ot Iztochna Evropa s parichen savet“, Minasyan. G., S, 2004 [2, c.3]

[3] ТЪРОУ, Лестър. Бъдещето на капитализма: Как днешните икономически сили оформят утрешният свят. София: Весела Люцканова, 2000. ISBN 954-8453-45-2. ; Tarou, L, „Badeshteto na kapitalizma“, S., 2000, IK"Vesela Lyuckanova" [3, c.4]

\section{Информация за автора:}

Доц. Йосиф Аврамов, доктор по икономика, Нов български университет, E-mail: avramov josif@abv.bg, тел. 029834562.

\section{Contacts:}

Ass. Prof. Joseph Avramov, doctor by economy, New Bulgarian University, e-mails: avramov_josif@abv.bg, Phone 029834562

Дата на постъпване на ръкописа (Date of receipt of the manuscript): 17.09.2020

Дата на приемане за публикуване (Date of adoption for publication): 27.09.2020 